\title{
MARTIN TI
}

BATERT CLEARANCE OETAINEO, RGCKSE RE

THE PUBLIC IS APRROVED RROCEOURES

ARE OH DLE WN THE REC CWNS SECTIOH,

$\frac{8}{9}$
$\frac{9}{6}$
$\frac{5}{8}$

MALTIN OOMIPANY 


\section{DISCLAIMER}

This report was prepared as an account of work sponsored by an agency of the United States Government. Neither the United States Government nor any agency Thereof, nor any of their employees, makes any warranty, express or implied, or assumes any legal liability or responsibility for the accuracy, completeness, or usefulness of any information, apparatus, product, or process disclosed, or represents that its use would not infringe privately owned rights. Reference herein to any specific commercial product, process, or service by trade name, trademark, manufacturer, or otherwise does not necessarily constitute or imply its endorsement, recommendation, or favoring by the United States Government or any agency thereof. The views and opinions of authors expressed herein do not necessarily state or reflect those of the United States Government or any agency thereof. 


\section{DISCLAIMER}

Portions of this document may be illegible in electronic image products. Images are produced from the best available original document. 


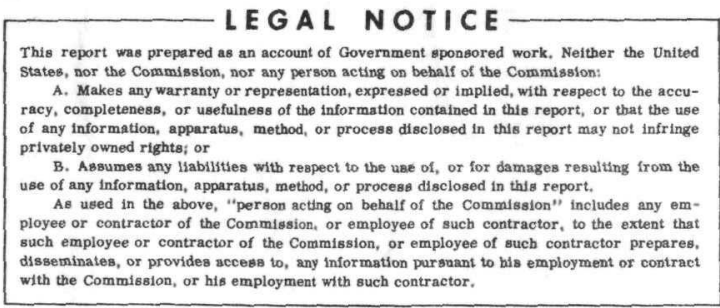

SFECIFTCATON

$\operatorname{tag}$

PLASMA ARC TWEST

a

SNAP 19 FUTL CAPSUI.ES

by

W. B. Wabs

2AND-3163-16

Approvediby: $\frac{7 \text { Dobuy / DCa }}{x_{0} y_{0} \text { Defry }}$

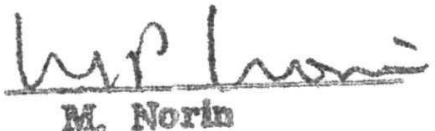

a Norix

there is no owjection from the patent view to the publication or point of view to tho of this docu
distemination otent Group
HY Patel 9 le 1964 


\section{IBST OF IFGUSES}

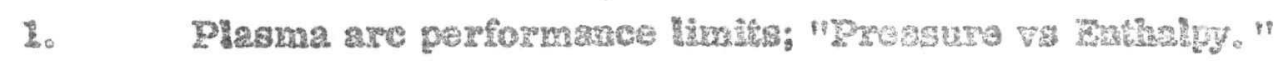

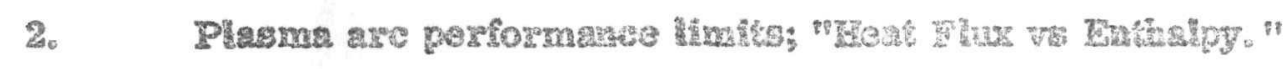

3. Low pressure iacility.

4. Meditum pressure fecilth

5. Control asd dats gethering eossoles.

6. Typical test spectroes ecarigaration.

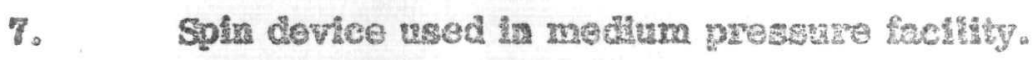

\section{LIST OF TABLES}

3. Theorefted ro-entry scaditiens

2. Dnta point values for series $\xi_{0} 2$ axd 2

3. Tua 


\author{
ABSTRACT \\ L TNTEODUCMON \\ 蕰 APPBOACR \\ III TEST PROCEDURE \\ A. Fecilduser \\ B. Spea \\ C. Mothod \\ KY. REIERENCES
}




\section{ANSTRACE}

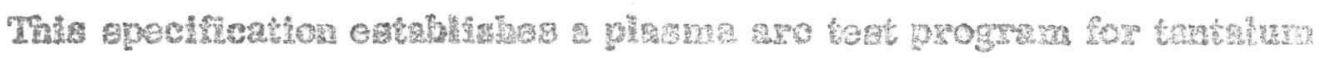
futo of the wall banta

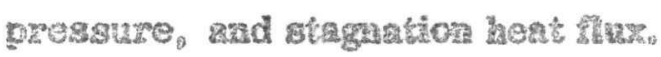




\section{MREODUCYYON}

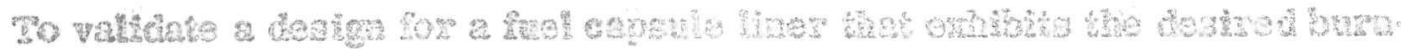

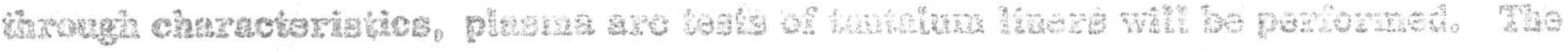

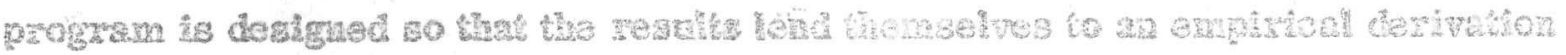
of a

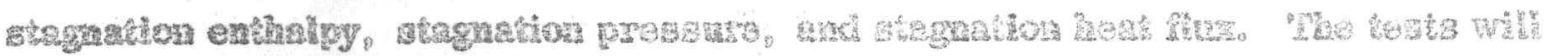

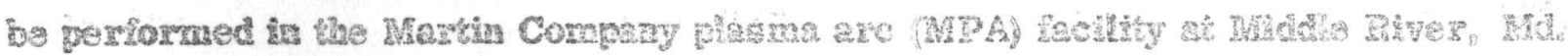

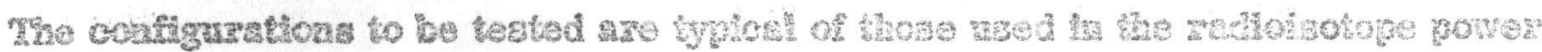

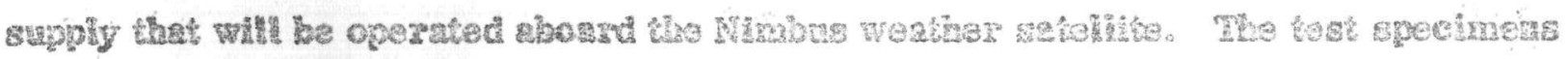

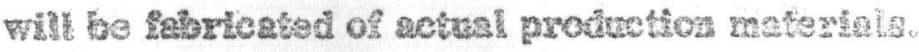

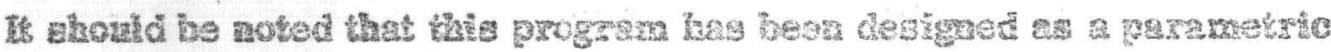

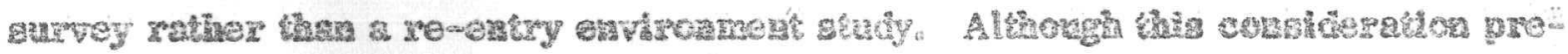

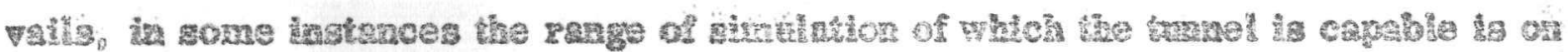

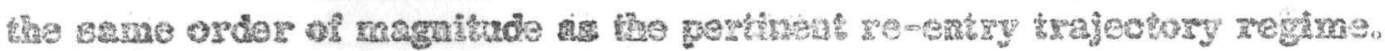

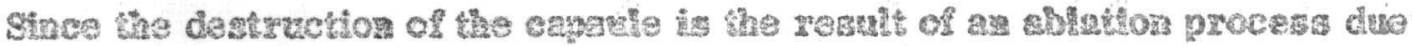

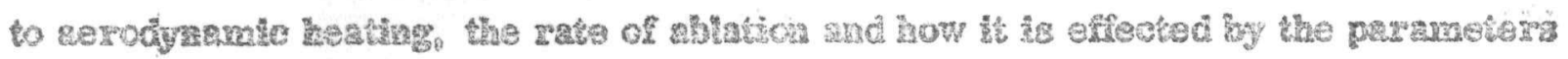

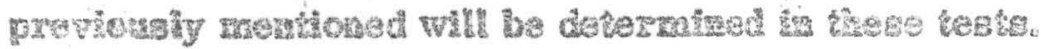

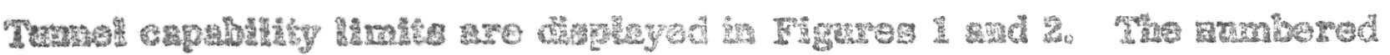

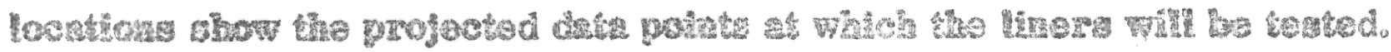




\section{FIGURE 1 \\ Plasma Arc \\ Performance Limits}

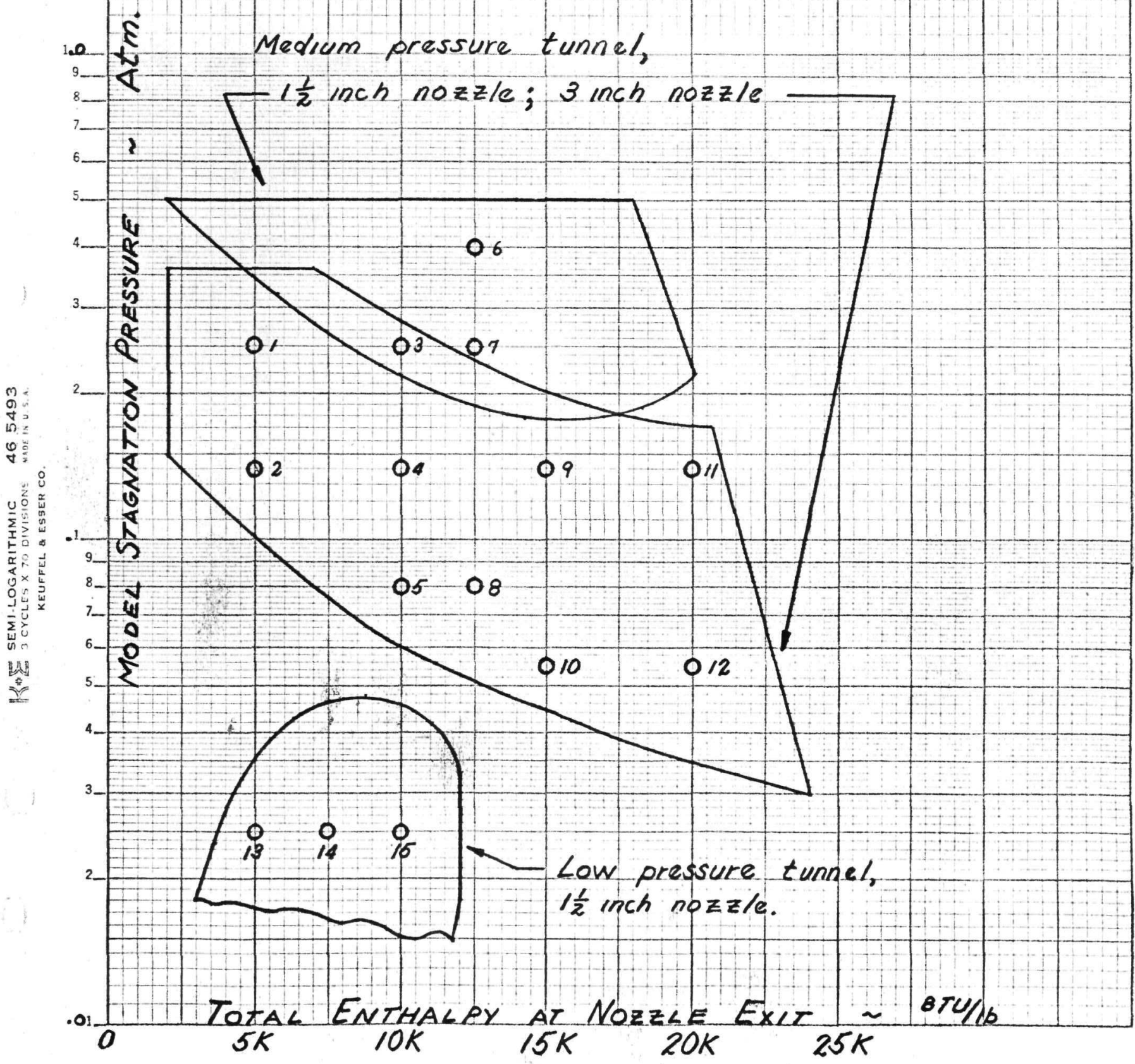




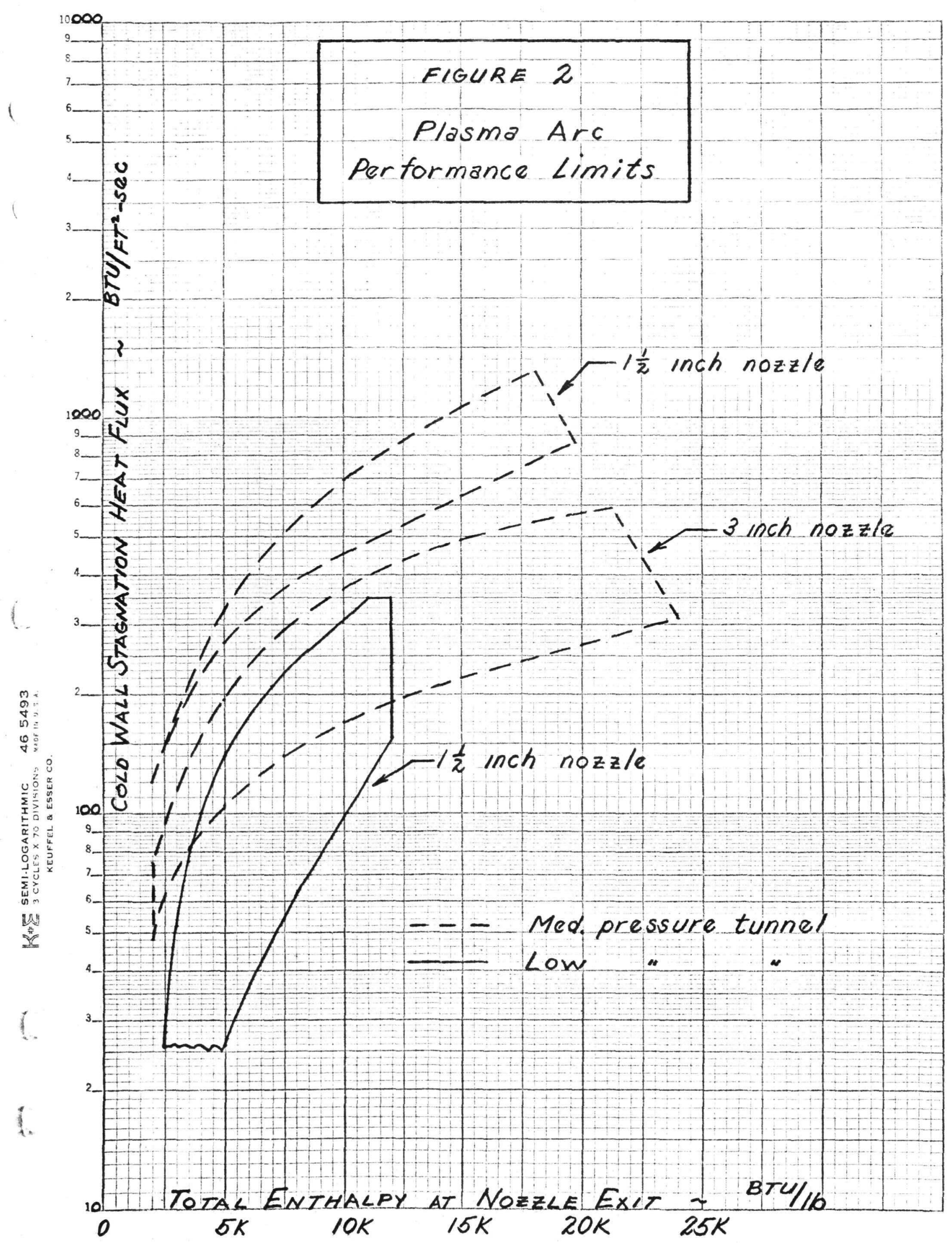




\section{H. APESOACE}

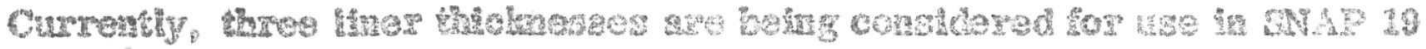

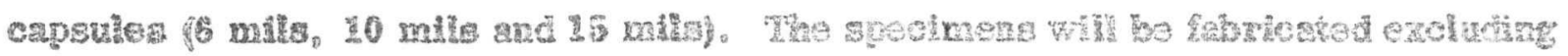

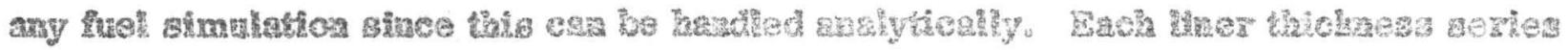

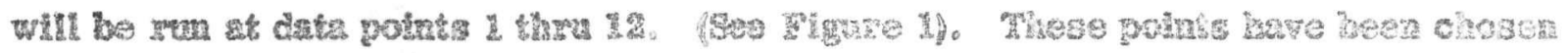

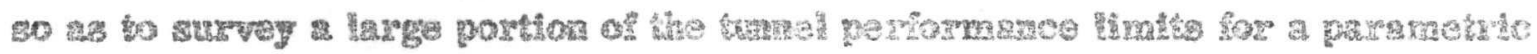

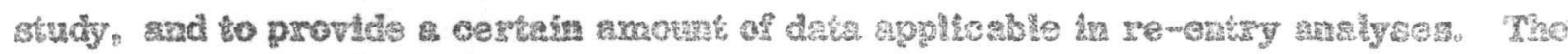
preln

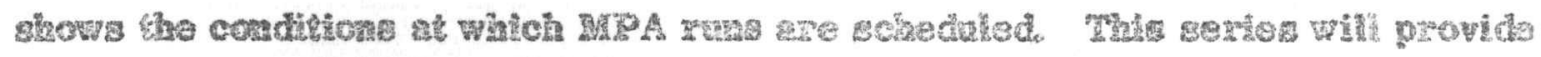

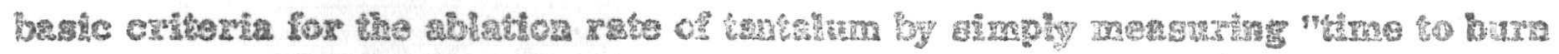
threxpgeng

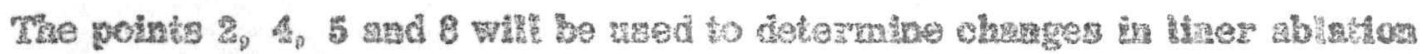

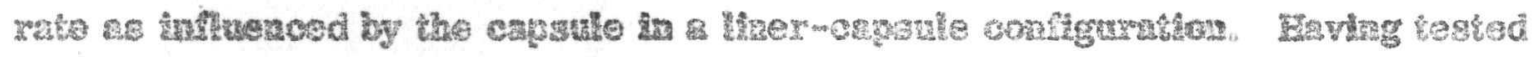

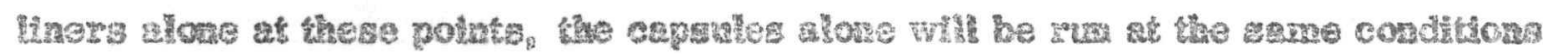

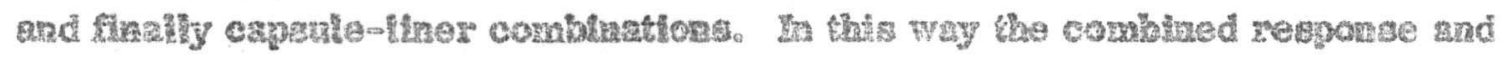
Haterescton cas be defined.

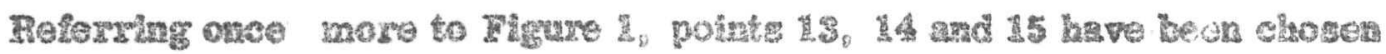

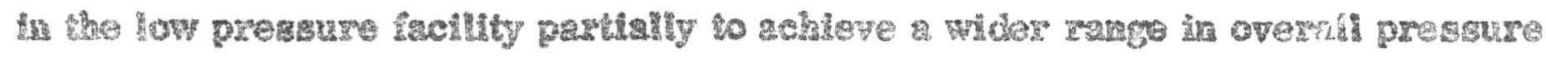

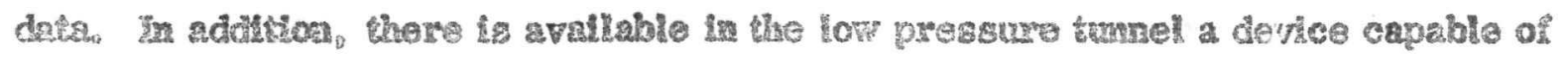

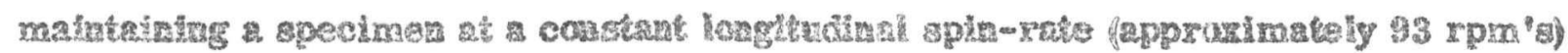

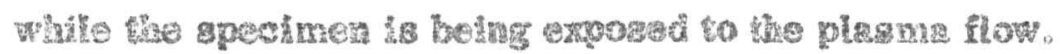




\section{MED

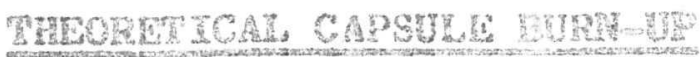

\begin{tabular}{|c|c|c|c|c|}
\hline & & 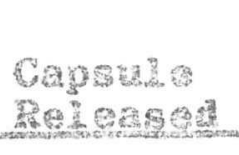 & 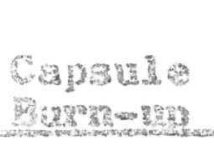 & 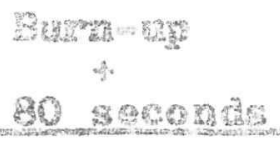 \\
\hline 路 & 웅 & 298,800 & 336,450 & $3 \% 5.980$ \\
\hline 䇺 3 & $3 \mathrm{~g}$ & 25.090 & 23.99 & $2 ? 870$ \\
\hline Mach & 4 & 29.6 & 25.6 & 15.2 \\
\hline $\mathrm{IH}_{\mathrm{SE}}$ & $\mathrm{gEV} / \mathrm{B}$ & 2. 2090 & $3 \mathrm{~B}, 4 \mathrm{~g}$ & 6.520 \\
\hline 89 & 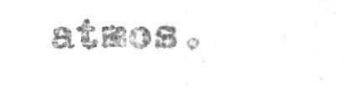 & 00796 & 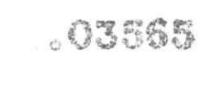 & - 38790 \\
\hline 85 & 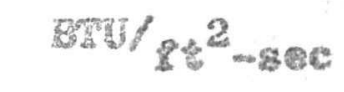 & 263 & 32 & 8要照 \\
\hline
\end{tabular}



.

BAARE

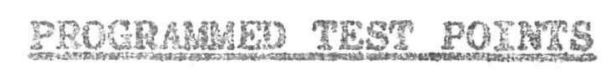

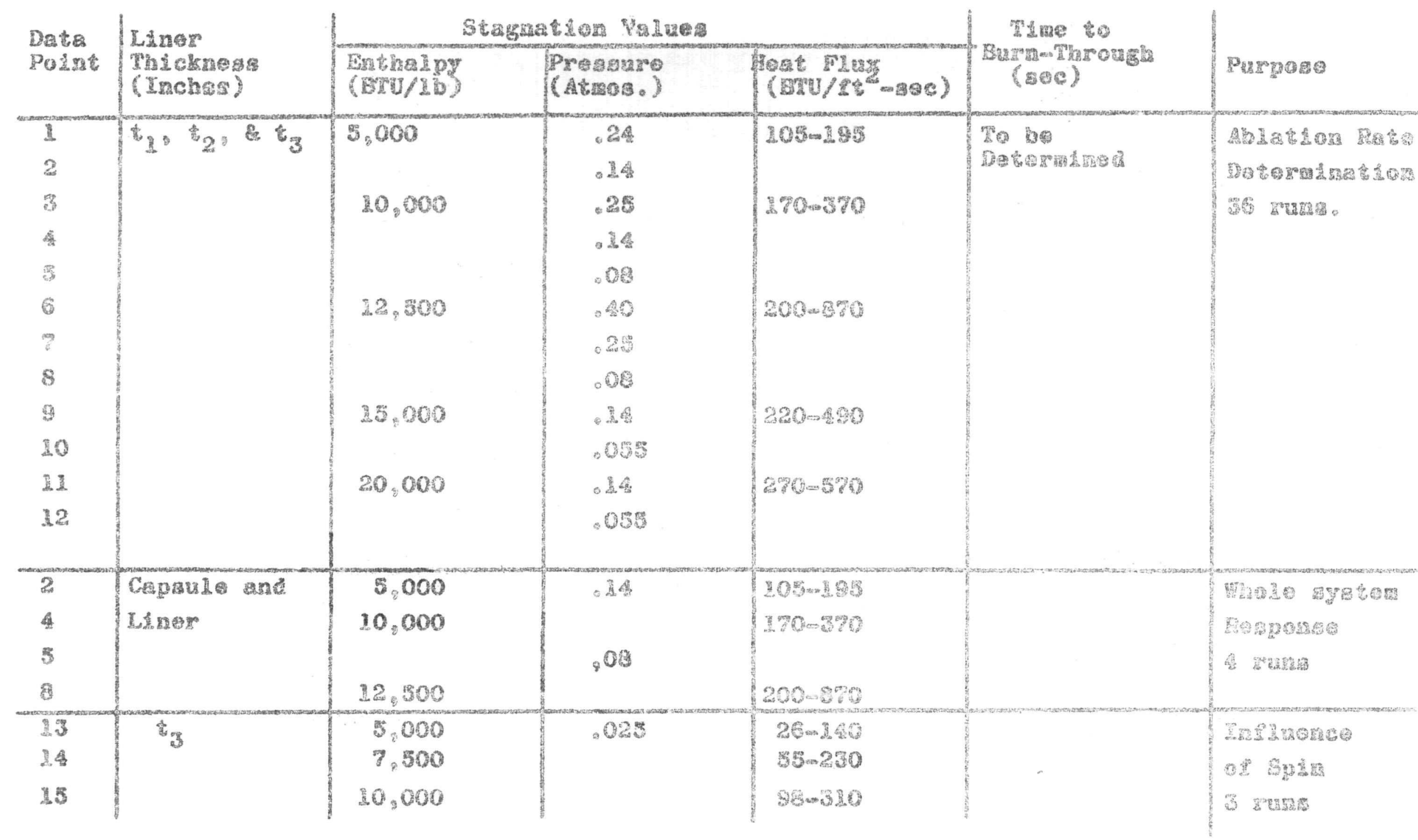




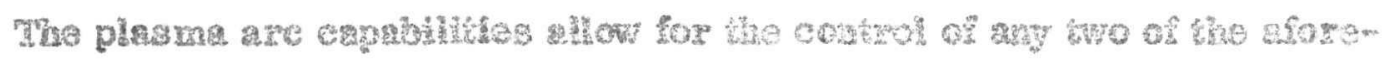

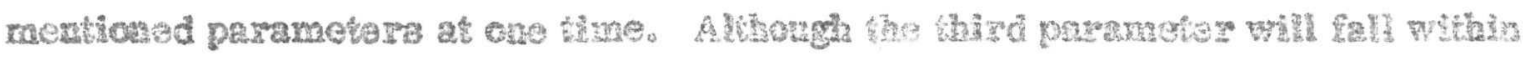

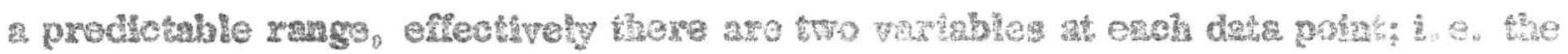

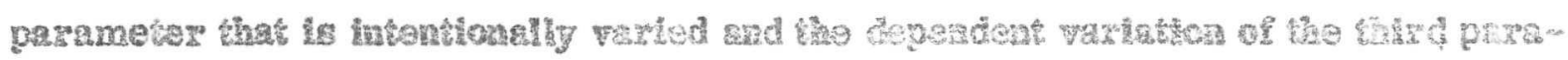

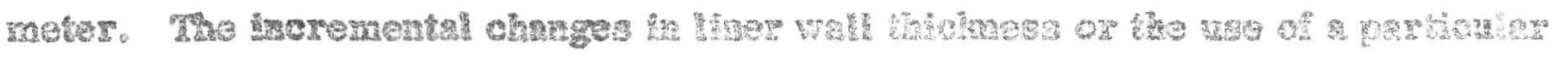

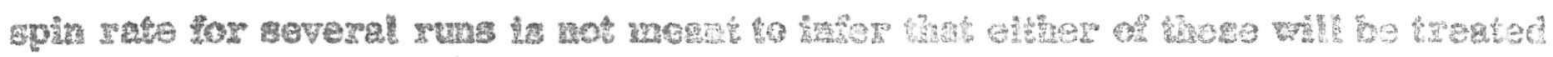

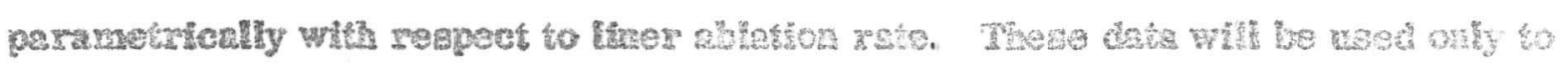

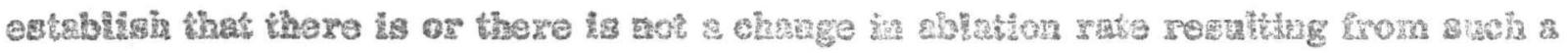
change an condtitions:

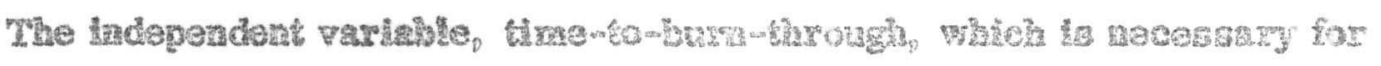
catch:

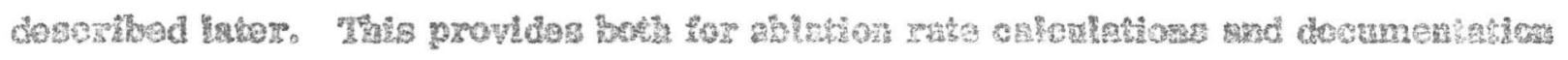
of eash nog

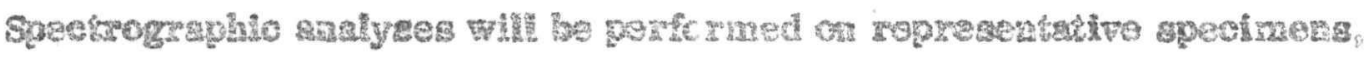

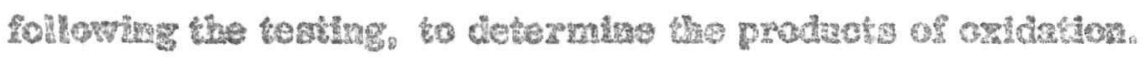




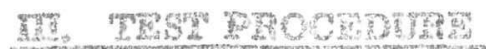

\section{A. grecilibies}

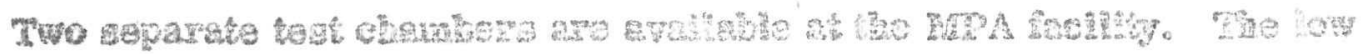

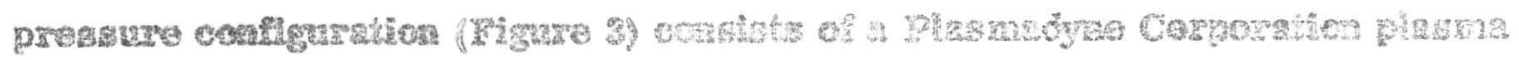

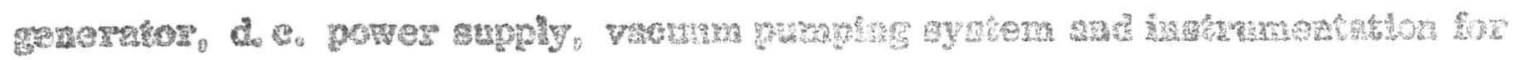

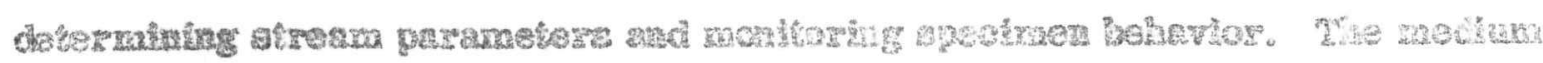

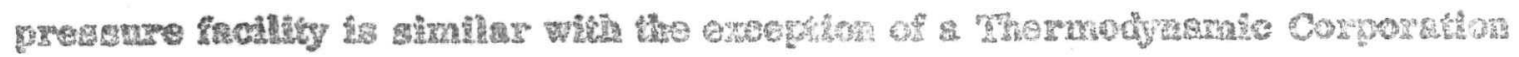

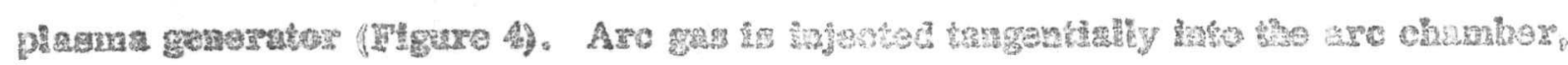

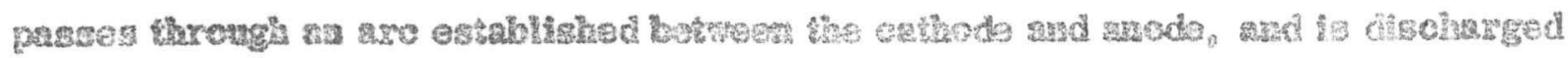

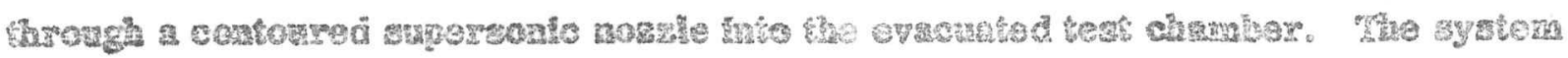

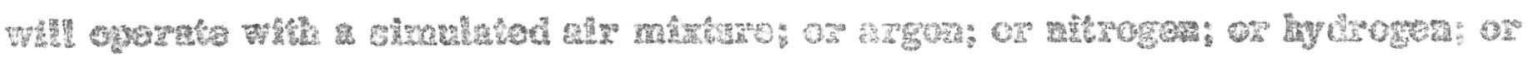

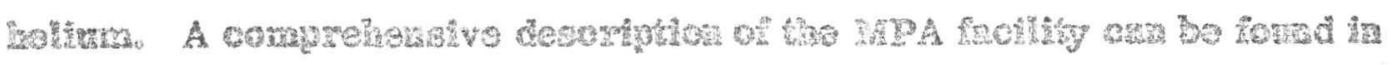
zefervaged:

Although some sligh method diffonenses may cecur botwees MPA turwels

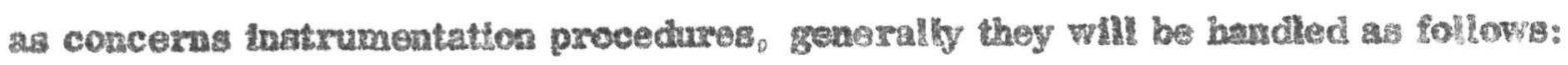

\section{Borthaly.}

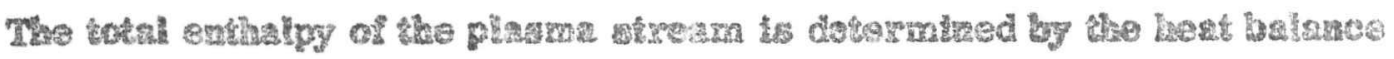

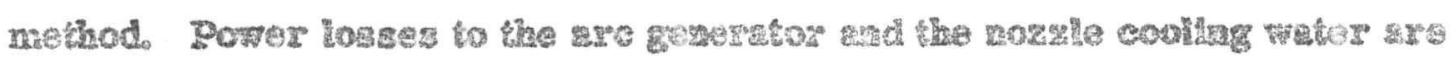

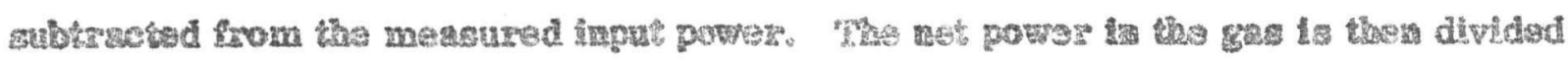

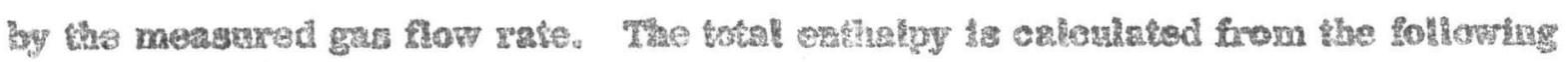

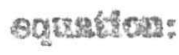

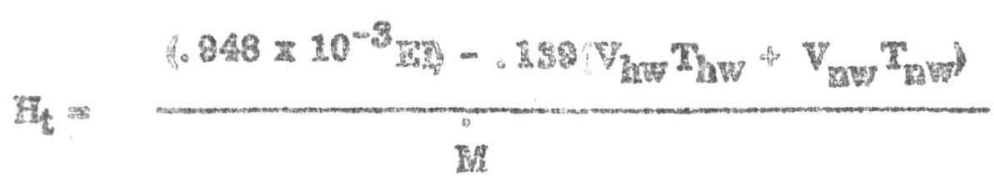


$\infty \quad$

0

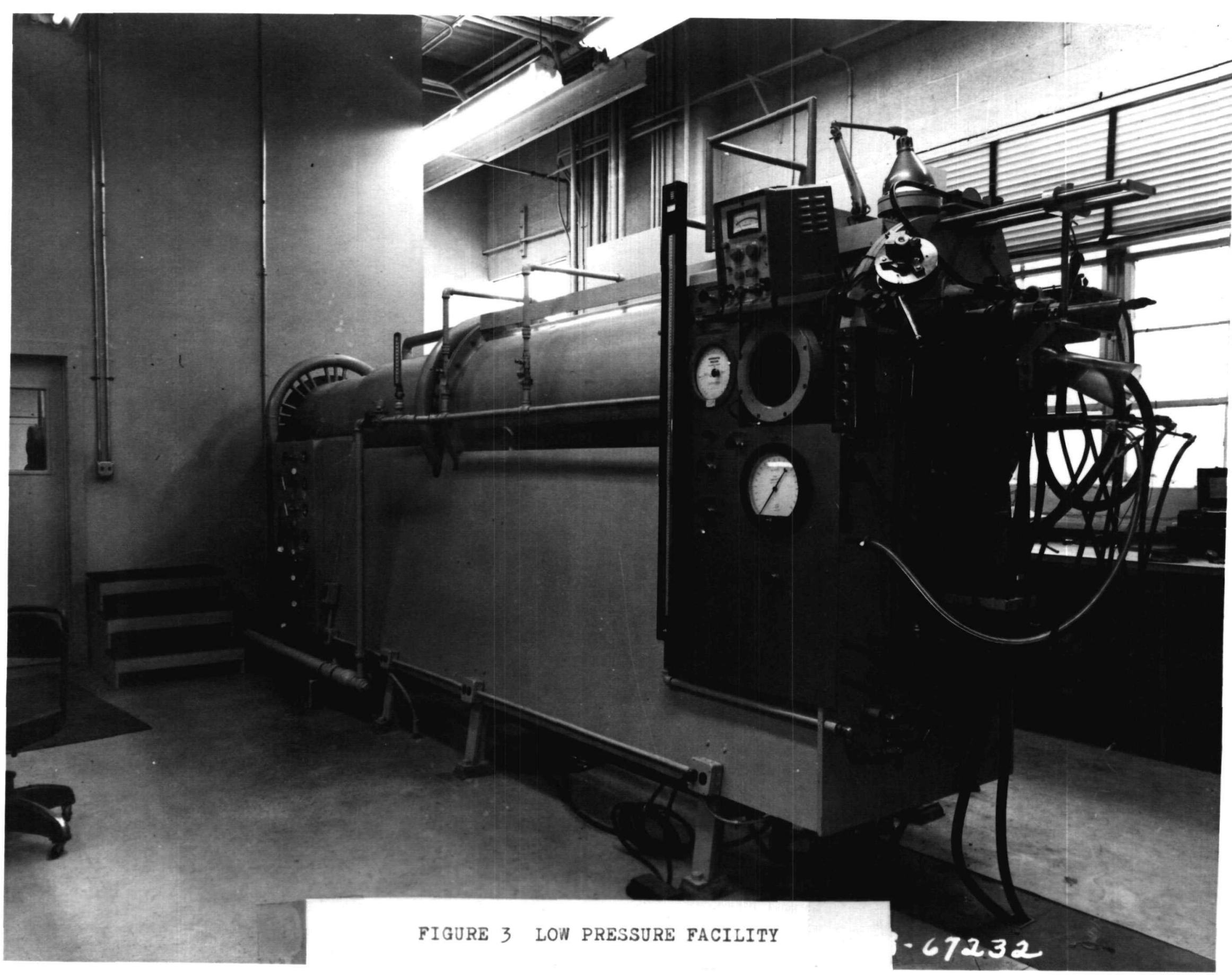




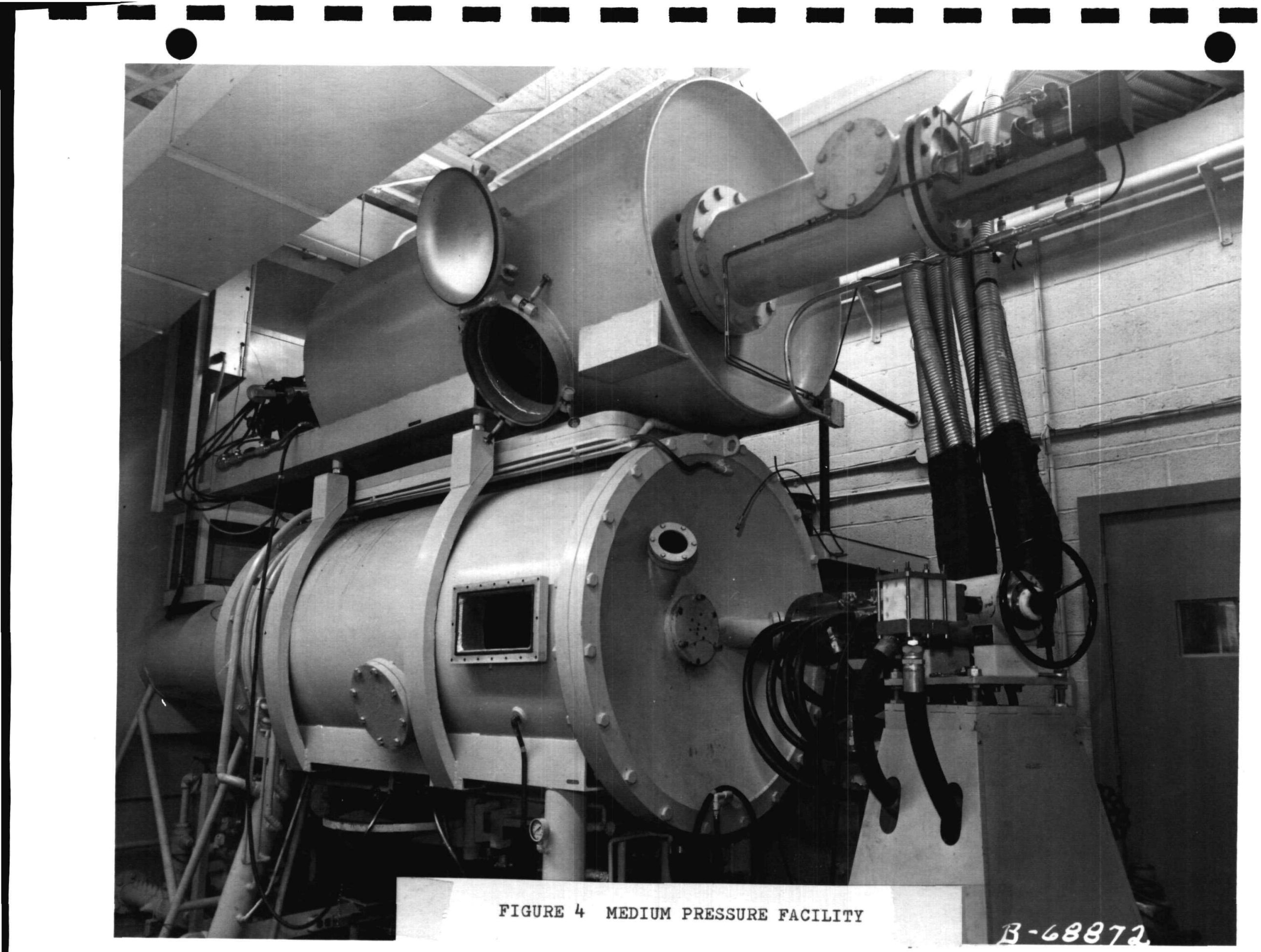




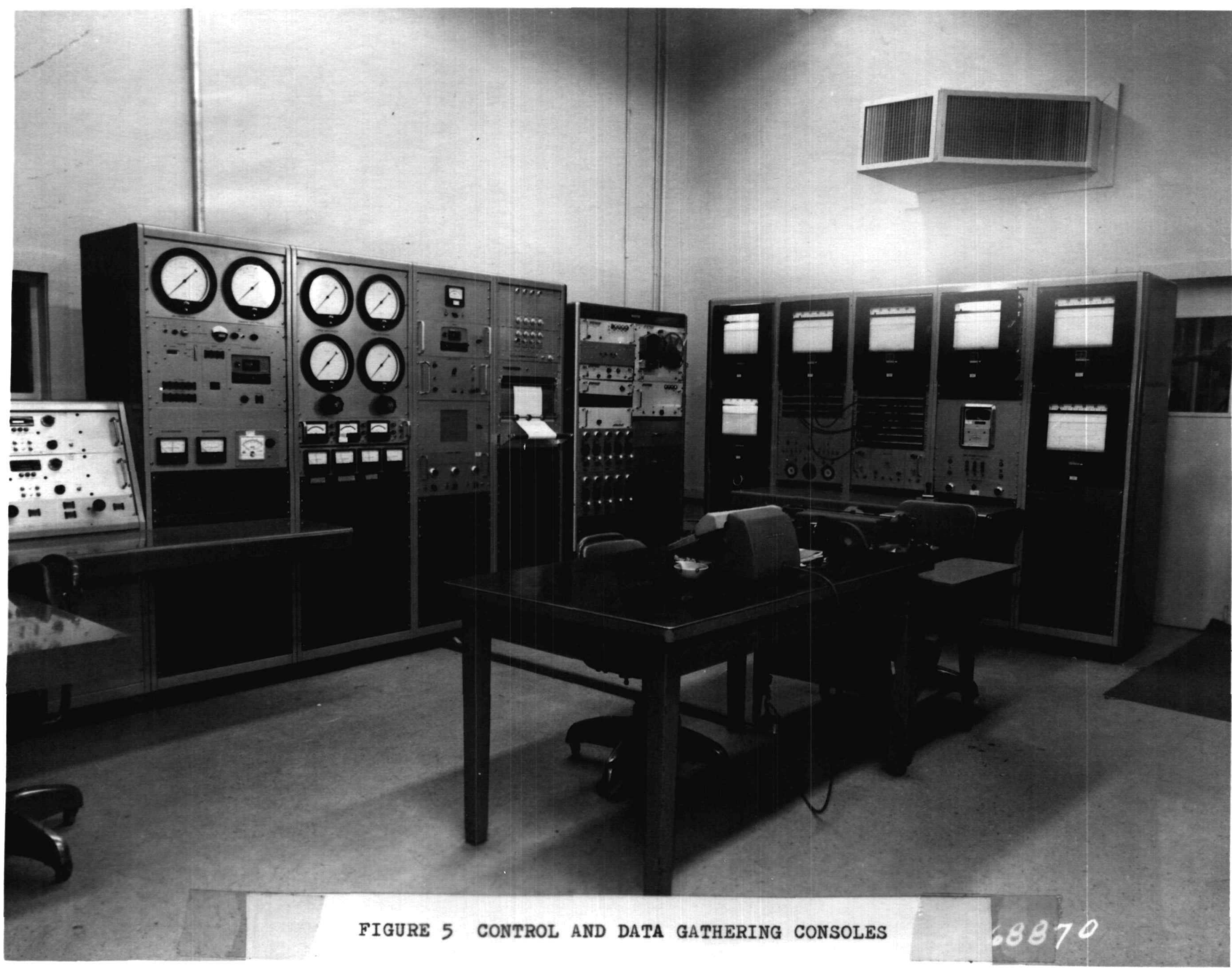




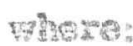

\begin{tabular}{|c|c|c|}
\hline $\mathrm{x}_{\mathrm{z}}$ & Totall gutholph & WTEAB \\
\hline $\mathrm{E}$ & = Voltage & volits \\
\hline 策 & $=$ Curreat & Ampondes \\
\hline$V_{\text {his }}$ & are generatos coo触学 & mest \\
\hline $\mathbf{T}_{\text {hw }}$ & 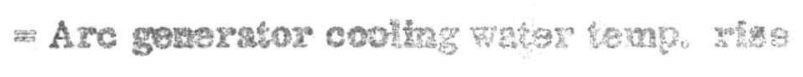 & res \\
\hline$V_{x w}$ & Nonglo cooling watar & CP跣 \\
\hline $\mathrm{T}_{\mathrm{aW}}$ & 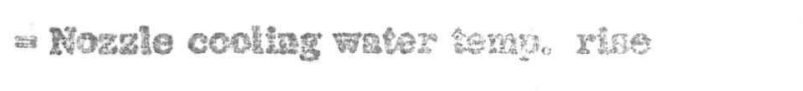 & 茞 \\
\hline M & 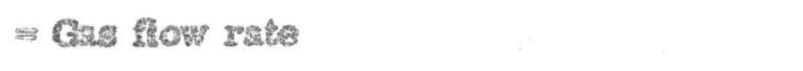 & $\mathrm{Ea} / \mathrm{anc}$ \\
\hline
\end{tabular}

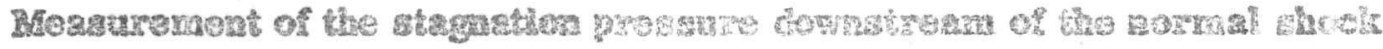

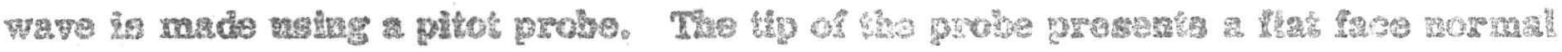

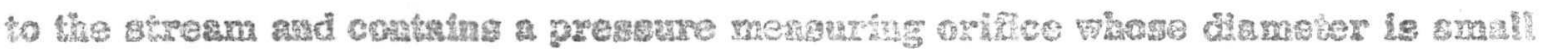

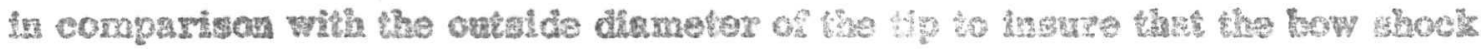

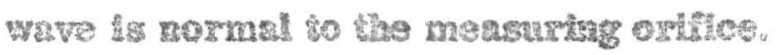

\section{Suz:iace Traperature}

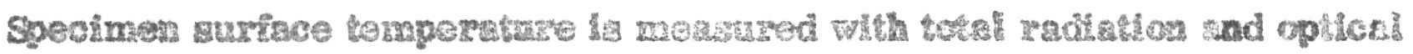

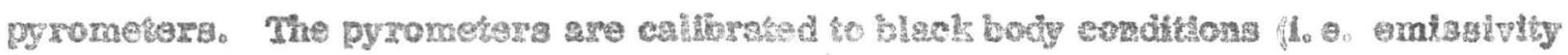

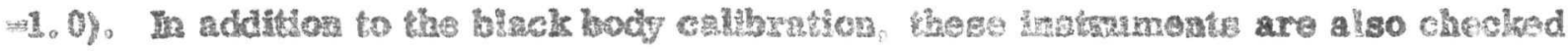

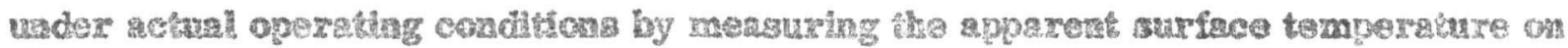

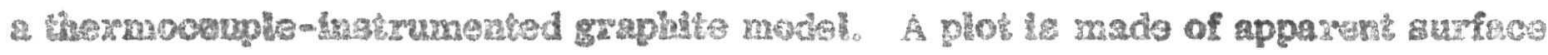

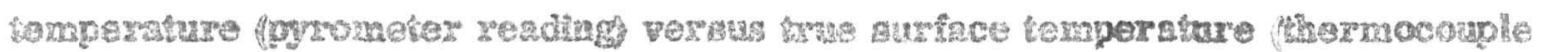

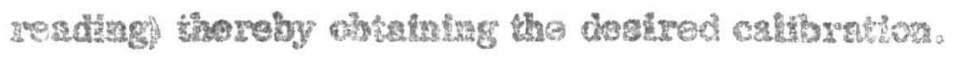




\section{Calorimeter}

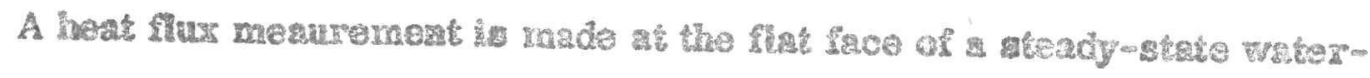

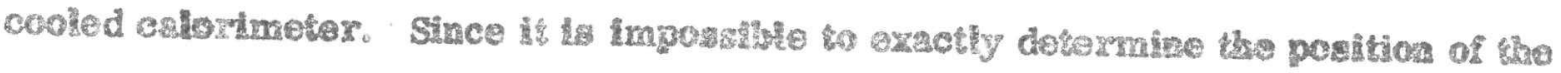

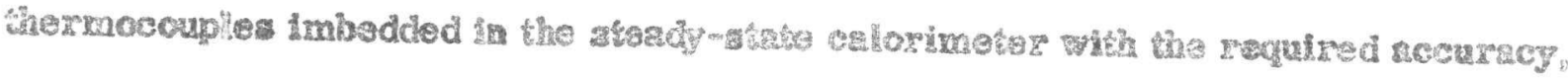

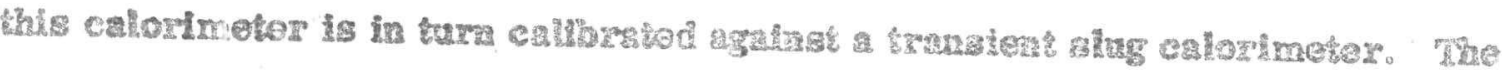

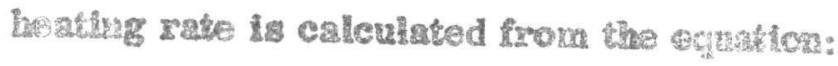

$$
\text { Qow }=\frac{W C 2}{A} \frac{\Delta}{\Delta T}
$$

พำลำ:

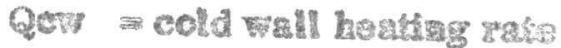

$$
\begin{aligned}
& \text { W weight of copper Besson }
\end{aligned}
$$

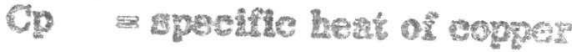

$$
\begin{aligned}
& \text { A m oxponed ares of copper gensor }
\end{aligned}
$$

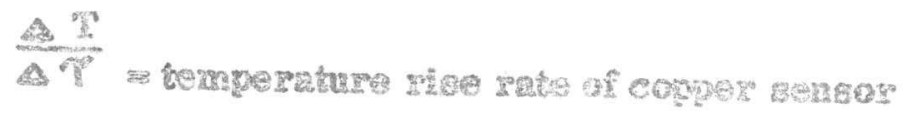

$$
\begin{aligned}
& \text { 5. Plootorgaphe }
\end{aligned}
$$

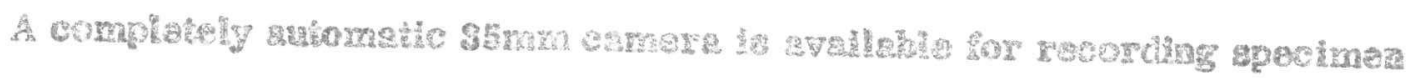

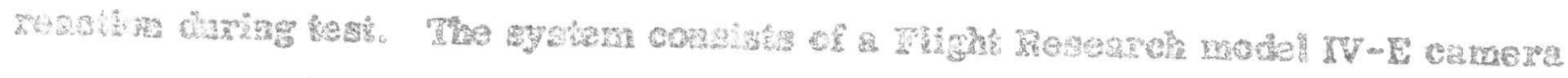

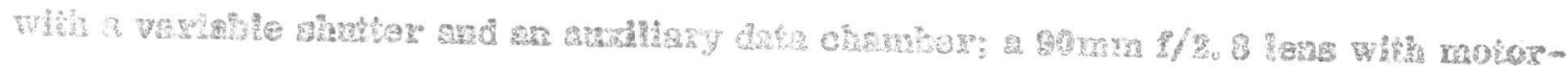

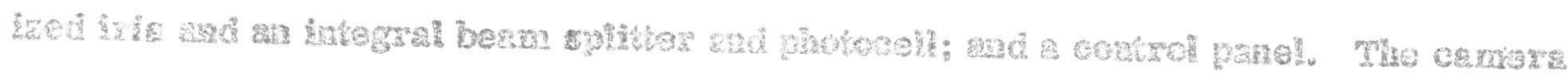

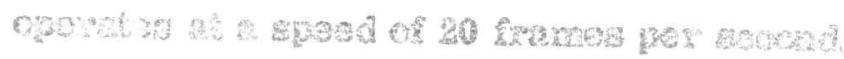


B. 3.

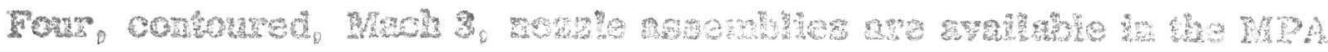

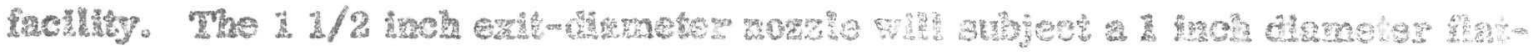

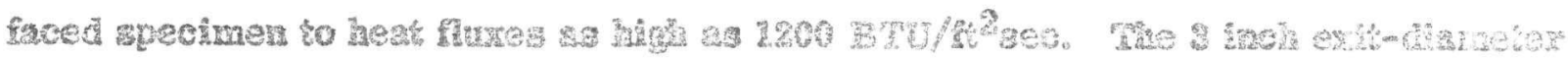

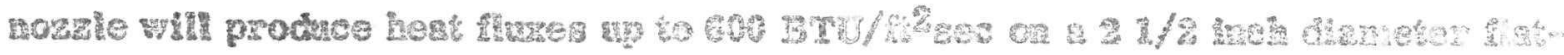

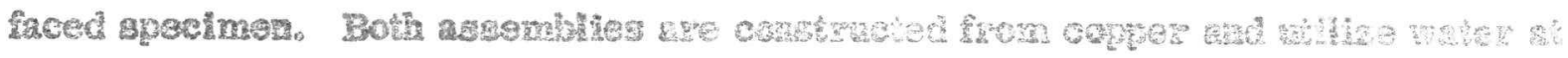
150 pal preasure sor coothg proweses.

B. Sresimens

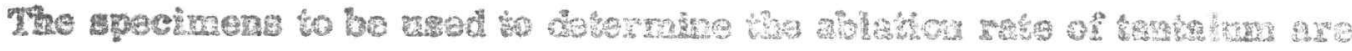

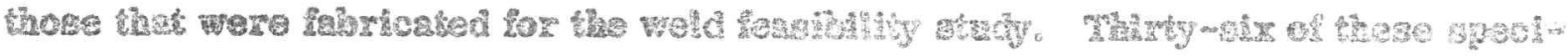

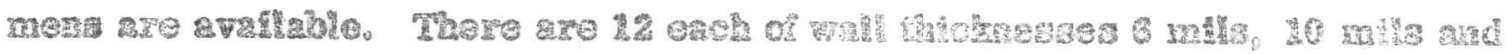

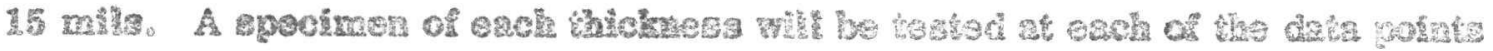

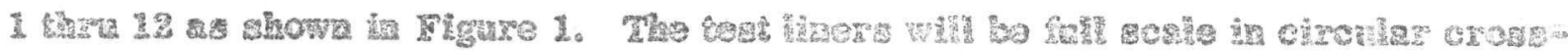

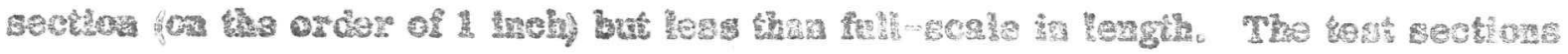

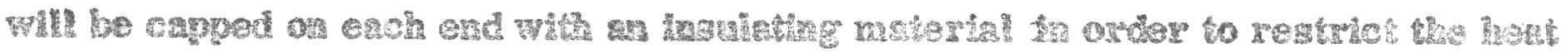

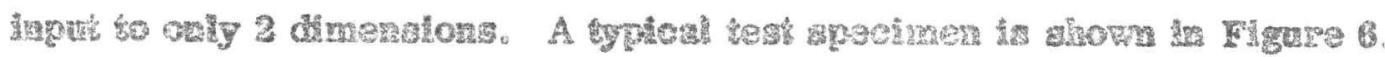

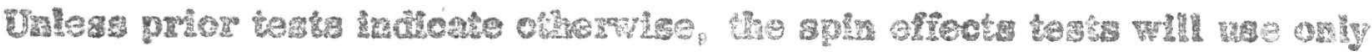

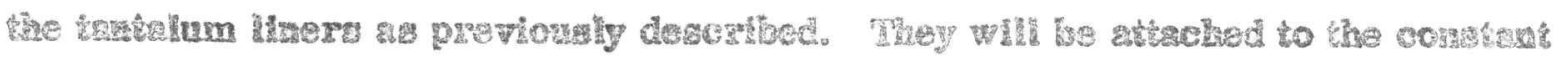

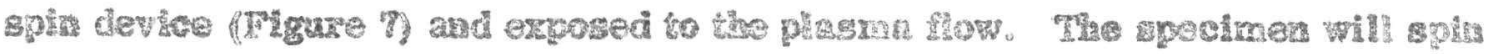

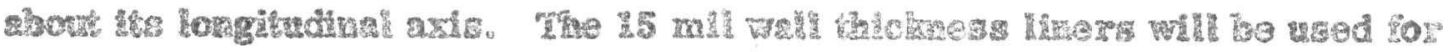

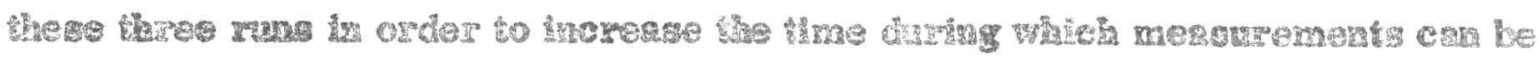
macis. 


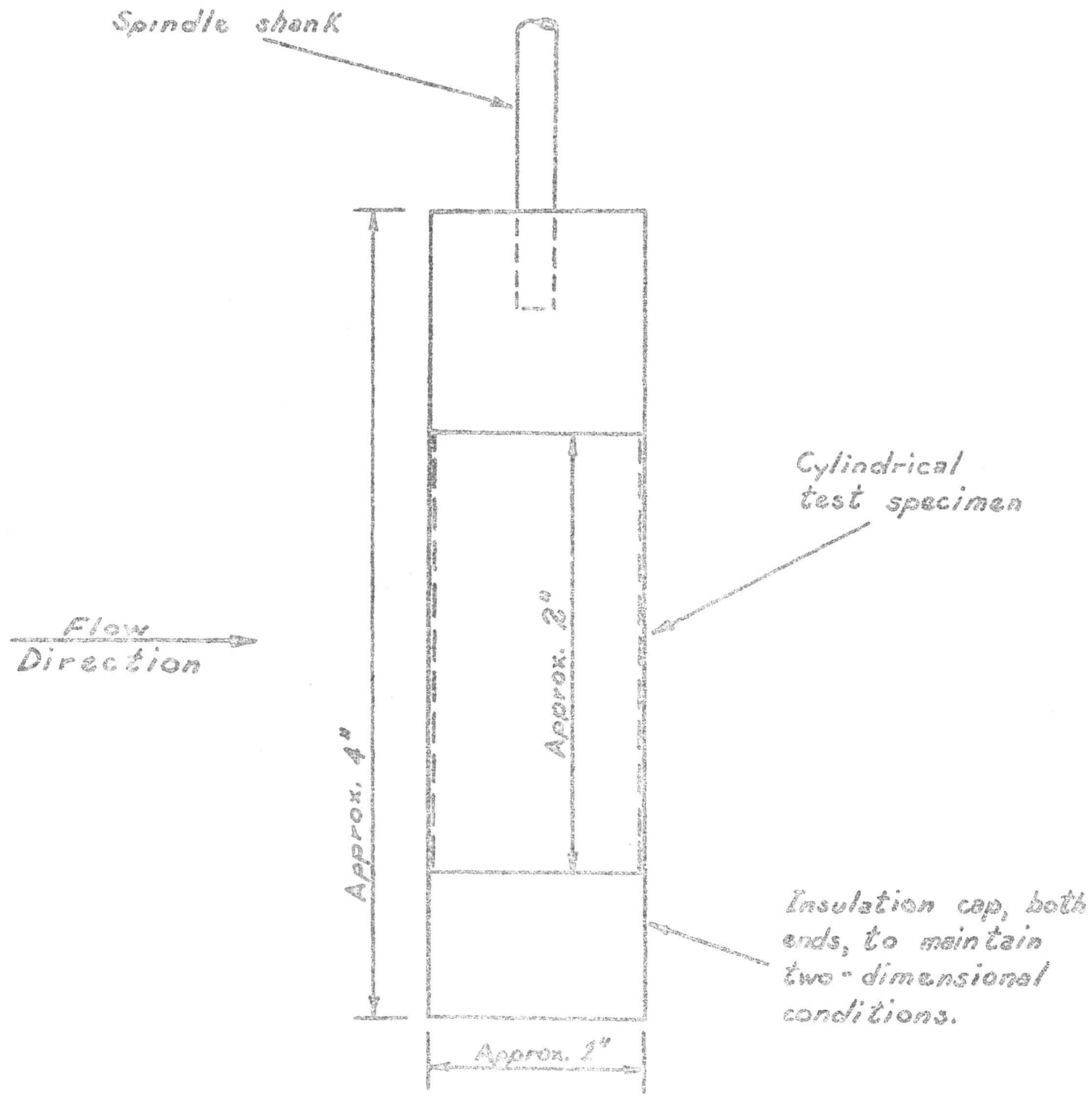

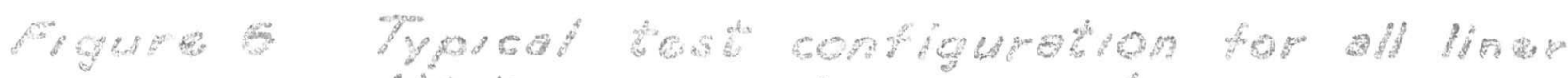
thakness molor copulas. 


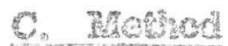

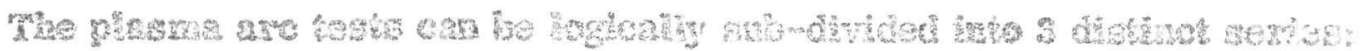

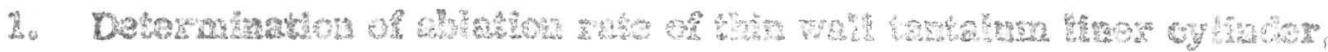

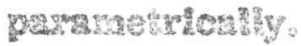

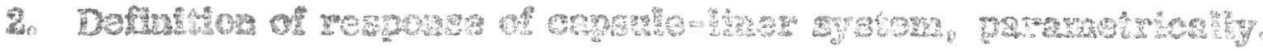

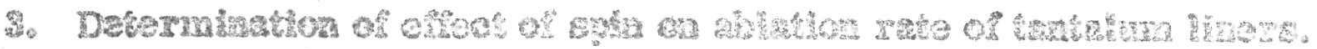

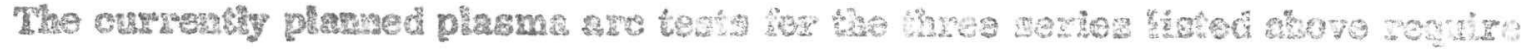

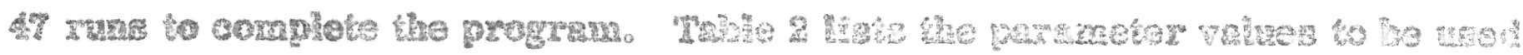

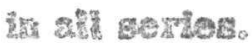

Tho a

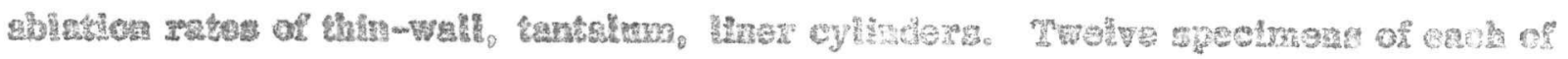

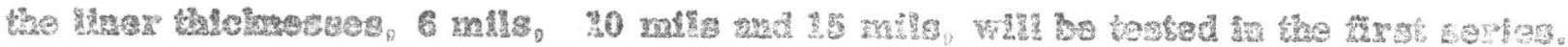

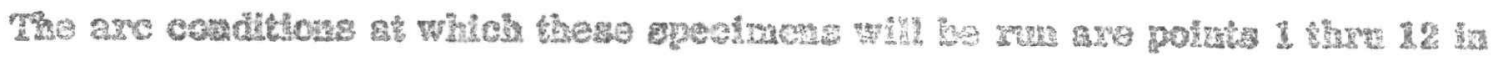

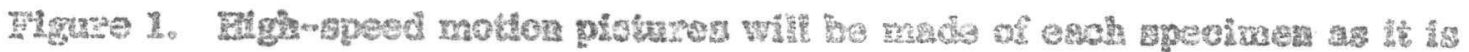

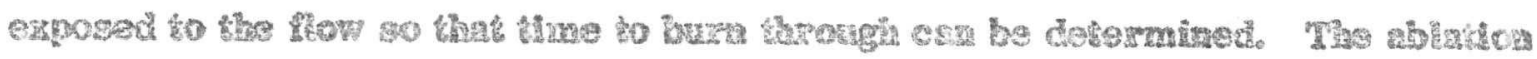

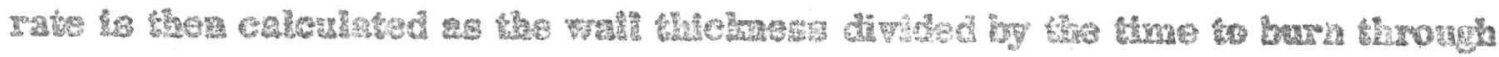

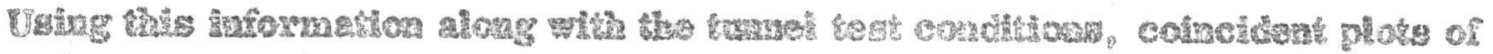

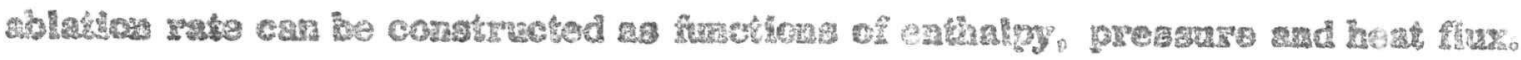
Fech postm

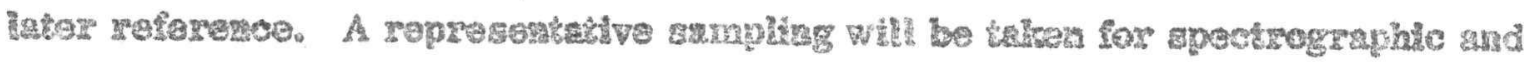

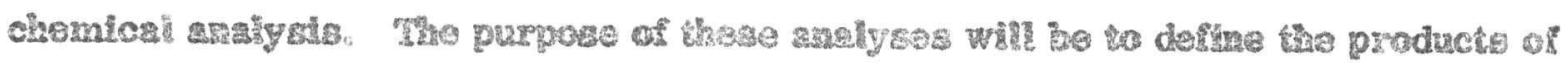

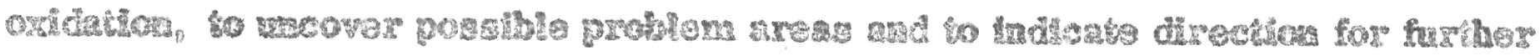

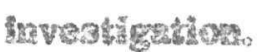




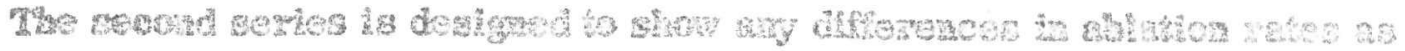

2 reguts of copalew

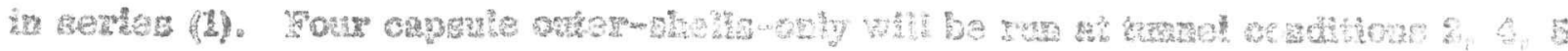

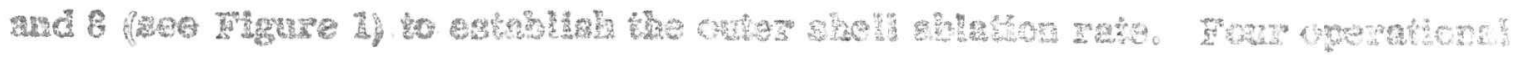

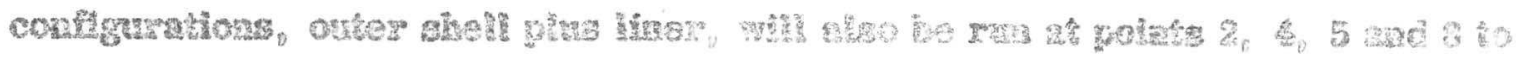

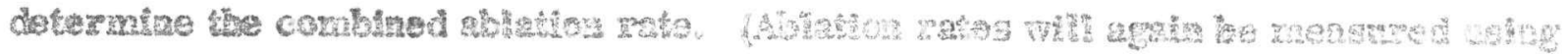
绿e hig

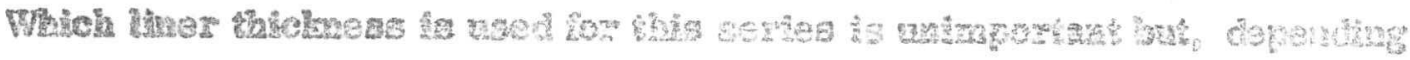

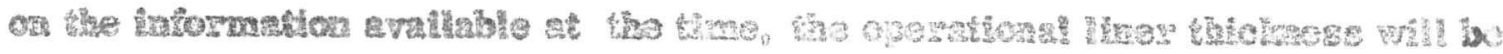

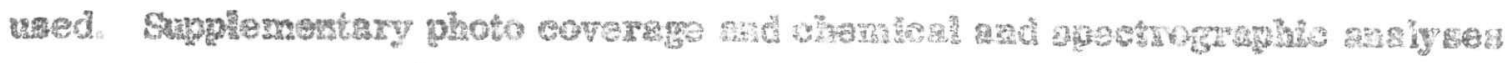

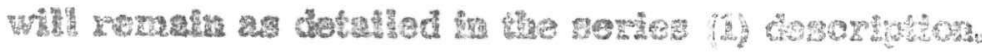

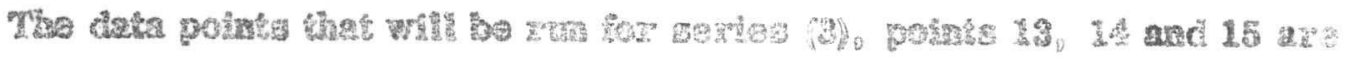

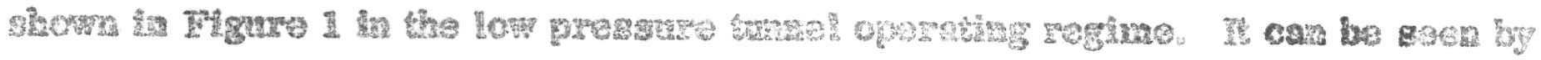

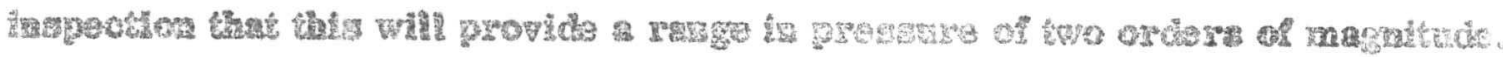

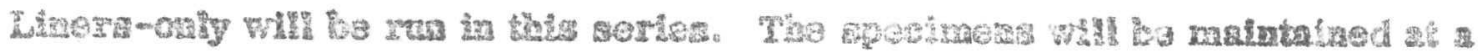

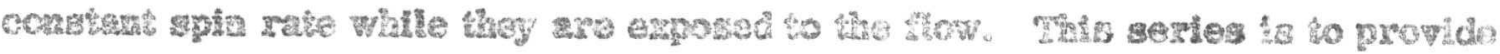
sane rats

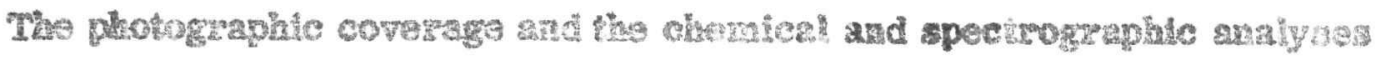

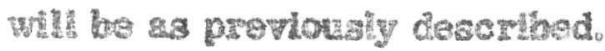

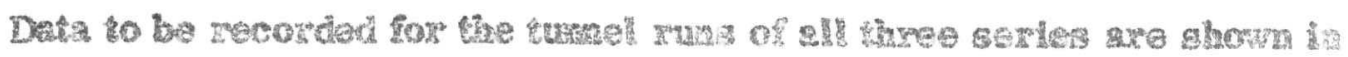
Table 3. 



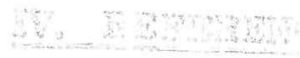

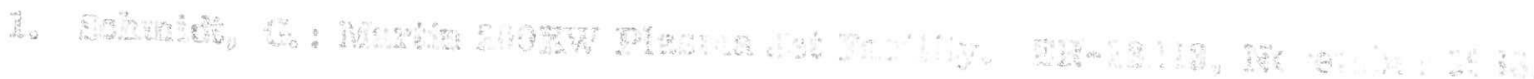

